\title{
Conditional expression of Mycobacterium smegmatis dnaA, an essential DNA replication gene
}

\author{
Rebecca Greendyke, ${ }^{1} \dagger$ Malini Rajagopalan, ${ }^{1} \dagger$ Tanya Parish ${ }^{2}$ \\ and Murty V. V. S. Madiraju ${ }^{1}$
}

1 Biomedical Research, 11937 US Hwy@271, The University of Texas Health Center at Tyler, Tyler, TX-75708-3154, USA

2 Department of Medical Microbiology, Barts and the London, Queen Mary's School of Medicine and Dentistry, Turner St, Whitechapel, London E1 2AD, UK

\author{
Author for correspondence: Murty V. V. S. Madiraju. Tel: +1 903877 2877. Fax : +1 9038775969 . \\ e-mail: murty.madiraju@uthct.edu
}

To begin to understand the role of Mycobacterium smegmatis dnaA in DNA replication, the $d n a A$ gene was characterized at the genetic level. Western analyses revealed that DnaA accounts for approximately $0 \cdot 18 \%$ of the total cellular protein during both the active and stationary growth periods. Expression of antisense dnaA RNA reduced viability, indicating that dnaA is an essential gene in replication. To further understand the role(s) of $d n a A$ in replication, a conditionally expressing strain was constructed in which expression of $d n a A$ was controlled by acetamide. Growth in the presence of $0.2 \%$ acetamide elevated the intracellular levels of DnaA and increased cell length, but did not affect viability. Visualization of DNA by fluorescence microscopy revealed that DnaA-overproducing cells were multinucleoidal, indicating a loss of synchrony between the replication and cell-division cycles. Withdrawal of acetamide resulted in the depletion of the intracellular levels of DnaA, reduced viability and gradually blocked DNA synthesis. Acetamidestarved cells were very filamentous, several times the size of the parent cells and showed either abnormal or multi-nucleoid morphology, indicating a blockage in cell-division events. The addition of acetamide to the starved cells restored their viability and shortened the lengths of their filaments back to the size of the parent cells. Thus, both increasing and decreasing the levels of DnaA have an effect on the cells, indicating that the level of DnaA is critical to the maintenance of coordination between DNA replication and cell division. It is concluded that DNA replication and cell-division processes in $M$. smegmatis are linked, and it is proposed that DnaA has a role in both of these processes.

Keywords: gene replacement, regulated expression, mycobacteria, DNA synthesis, filamentation

\section{INTRODUCTION}

Much of our understanding of chromosomal DNA replication initiation comes from detailed studies carried out in Escherichia coli, a fast-growing, Gram-negative bacterium. These studies have indicated that DnaA is the initiator of replication and, as a first step in the process, binds to DnaA boxes ( 9 nt long DnaA recognition sequences) located in the origin of replication

$\dagger$ These authors contributed equally to this work.

Abbreviations: oriC, origin of replication; kan, kanamycin; SCO, single crossover; DCO, double crossover; d.t., doubling time(s).
(oriC) (Kornberg \& Baker, 1991; Messer et al., 2001). This process entails the attachment of approximately 20-40 monomers of the DnaA protein complexed with ATP to oriC (Bramhill \& Kornberg, 1988a, b). These initial interactions lead to the formation of an open complex to which the DnaB helicase-DnaC complex is recruited, leading to the formation of a prepriming complex; this prepriming complex allows assembly of the DnaG primase and the establishment of replication forks (Gille \& Messer, 1991; Marszalek \& Kaguni, 1994). DnaA is an ubiquitous and evolutionarily conserved protein, and current thinking is that DnaA levels are growth rate constant (Hansen et al., 1991). One report has indicated that intracellular levels of E. coli 
DnaA are maintained at relatively constant levels, i.e. approximately 900-2100 molecules per cell, during both exponential growth and the transition to the stationary growth phase, and the DnaA levels seem to increase during the late-stationary growth phase (Ali Azam et al., 1999). Genetic studies carried out in organisms such as Bacillus subtilis (Moriya et al., 1990), Caulobacter crescentus (Gorbatyuk \& Marczynski, 2001) and Streptomyces spp. (Lee et al., 2002) have indicated that dnaA is an essential replication gene, whereas it is not essential for the survival of Synechocystis spp. (Richter et al., 1998).

The genus Mycobacterium includes fast-growing species, with doubling times (d.t.) of between 2 and $3 \mathrm{~h}$ (Mycobacterium smegmatis and Mycobacterium fortuitum) and $10 \mathrm{~h}$ (Mycobacterium avium-intracellulare complex), and slow-growing species, with d.t. of $24 \mathrm{~h}$ (Mycobacterium tuberculosis and Mycobacterium bovis) (Ratledge, 1976). Although M. smegmatis is viewed as a fast-growing member of the genus $\mathrm{Myco-}$ bacterium, its d.t. is approximately six to seven times slower than that of E. coli. In addition to their growth characteristics, some members of the mycobacteria, e.g. M. tuberculosis, are believed to maintain two physiologically distinct growth states - an active, multiplicative state and a dormant, non-replicative state (Manabe \& Bishai, 2000). In the latter state, the bacterium remains metabolically active but is in a state of non-growth for extended periods, only to revive and multiply and cause infection later. The non-replicative persistent state can be induced in vitro by growing the organisms under oxygen-depletion conditions (Dick et al., 1998; Wayne, 1977, 1994). These experiments also suggested that bacteria in the non-replicative, persistent state have completed DNA synthesis but are blocked at the cell-division stage; they also showed that the bacteria exhibited synchronous replication when resuspended in fresh growth media (Wayne, 1977; Wayne \& Hayes, 1996). The growth characteristics of M. smegmatis cultured under oxygen-depletion conditions are similar to those described for M. tuberculosis (Dick et al., 1998). The genetic elements responsible for the differences in growth rates and the ability to shift between the two physiologically distinct growth states remain unknown.

The genetic and biochemical aspects of replication initiation in members of the mycobacteria are poorly understood. To date, only the key elements involved in the replication initiation process in members of the mycobacteria, dnaA and oriC, have been identified and characterized (Madiraju et al., 1999; Qin et al., 1999; Rajagopalan et al., 1995; Salazar et al., 1996). Based on the results of a plasmid replication assay, we reported that the $d n a A-d n a N$ intergenic regions from M. smegmatis, $M$. avium and $M$. tuberculosis can function as oriC in each organism (Madiraju et al., 1999; Qin et al., 1999; Rajagopalan et al., 1995) and that point mutations in the designated DnaA boxes of $M$. smegmatis oriC severely decrease oriC activity (Qin et al., 1997). These results are different from those reported for E. coli, where single, double or triple mutation combinations in two or three DnaA boxes did not affect plasmid-based oriC replication (Holz et al., 1992; Langer et al., 1996). The nucleotide sequences of the oriC region in members of the mycobacteria are approximately $65 \%$ similar, and many of the designated DnaA boxes in mycobacterial oriC are positionally conserved (Madiraju et al., 1999; Qin et al., 1999), even though mycobacterial oriC genes are species-specific (Madiraju et al., 1999; Qin et al., 1999). DnaA of M. tuberculosis has been purified, and its interactions with oriC and adenine nucleotides and the effects of acidic phospholipids on these interactions have been investigated (Yamamoto et al., 2002). At the deduced amino acid sequence level, mycobacterial DnaA proteins are approximately $82 \%$ similar, with differences noted in the amino acids located between residues 100 and 160 . The conserved regions are believed to contain the lipid-, ATP- and DNA-binding domains (Messer et al., 2001; Schaper \& Messer, 1997; Skarstad \& Boye, 1994). While these and other studies suggest a relationship between $d n a A$ and oriC, it is unknown as to whether the $d n a A$ gene is essential in any members of the mycobacteria and, if it is, whether it is needed for replication. Here, we show that the M. smegmatis dnaA gene is an essential replication gene and that cells containing altered levels of DnaA are filamentous and multinucleoidal. The implications of these results for understanding the function of M. smegmatis DnaA are discussed.

\section{METHODS}

DNA and plasmids. Relevant plasmids and bacterial strains used in the study are listed in Table 1.

Molecular biology protocols. Unless stated otherwise, all PCR fragments were first cloned into the TA vector (Promega) prior to their subcloning into other vectors. All standard molecular biological procedures were performed essentially as described by Sambrook et al. (1989). The nucleotide sequences of all of the $d n a A$ amplification products were confirmed by sequencing using an ABI Prism automated DNA sequencer.

Construction of a dnaA antisense expression vector. The $M$. smegmatis dnaA coding region was amplified by PCR using the oligonucleotide primers MVS1 (5'-GCGGATCCAATGACTGCTGACCCCGAC- $3^{\prime}$ ) and MVM72 (5'-CAGGATCCGGTGTGGAGAGATTC-3') and cloned in the antisense orientation into pMV261, an E. coli-Mycobacterium shuttle vector, under the transcriptional control of the hsp60 promoter (Stover et al., 1993). The BamHI restriction sequence is shown in bold. The recombinant plasmid, pMBL9, was electroporated into M. smegmatis and transformants were selected at $30^{\circ} \mathrm{C}$. Antisense expression was induced by shifting growth cultures to higher temperatures, i.e. 37 and $44^{\circ} \mathrm{C}$. One merodiploid expressing $d n a A$ antisense RNA (also referred to as and A), BLM4, was selected and used.

\section{Construction of $d n a A$ expression vectors}

$d n a A$ from the native promoter. A DNA fragment containing the putative $d n a A$ promoter and its coding region from $M$. smegmatis was amplified by PCR from pMR40 (Rajagopalan et al., 1995) using the oligonucleotide primers MVM30 (5'TTGTTCGGCTGGAAGGTCCGCT-3') and MVM72. The DNA fragment was then released from the TA vector by digestion with NotI and cloned into pMV306, an integration- 
Table 1. Bacterial strains and plasmids used in this study

\begin{tabular}{|c|c|c|}
\hline Strain/plasmid & Description and relevant genotype & Source \\
\hline \multicolumn{3}{|l|}{ Strain } \\
\hline $\mathrm{mc}^{2} 155$ & Laboratory strain; $d n a A^{+}$(wild-type) & Snapper et al. (1988) \\
\hline RGM15 & $\mathrm{SCO} ; d n a A^{+}, l a c Z, a p h, s a c B, \Delta d n a A$ & This study \\
\hline RGM18 & $\begin{array}{l}\text { SCO plus integrating vector; } d n a A^{+}, \operatorname{lac} Z, a p h, s a c B, \Delta d n a A, d n a A^{\mathrm{Msm}-\mathrm{gtg}}, \text { byg } \\
\text { (merodiploid) }\end{array}$ & This study \\
\hline RGM27 & $\begin{array}{l}\text { SCO plus integrating vector; } d n a A^{+}, l a c Z, a p h, s a c B, \Delta d n a A, d n a A \text { from native } \\
\text { promoter, hyg }\end{array}$ & This study \\
\hline RGM34 & SCO plus integrating vector; $d n a A^{+}, l a c Z, a p h, s a c B, \Delta d n a A, d n a A^{\mathrm{Msm}-\mathrm{ttg}}$, byg & This study \\
\hline RGM35 & Integrating vector in wild-type; $d n a A^{+}, d n a A^{\mathrm{Msm}-\operatorname{ttg}}, h y g$ (dnaA merodiploid) & This study \\
\hline RGM36 & 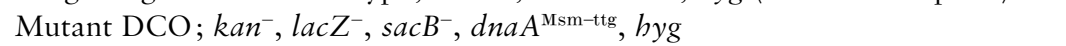 & This study \\
\hline BLM4 & Wild-type plus pMV261 expressing $d n a A$ antisense RNA; $d n a A^{+}$, and $A, a p h$ & This study \\
\hline \multicolumn{3}{|l|}{ Plasmid } \\
\hline pMV261 & E. coli-Mycobacterium shuttle vector carrying $h s p 65$ promoter cassette; kan $^{\mathrm{r}}$ & Stover et al. (1991) \\
\hline pMV306 & Integration proficient E. coli-Mycobacterium shuttle vector; hyg $^{\mathrm{r}}$ & Stover et al. (1991) \\
\hline pMR40 & $4 \mathrm{~kb}$ M. smegmatis dnaA region in pUC18 derivative; $\mathrm{kan}^{\mathrm{r}}$ & Rajagopalan et al. (1995) \\
\hline p2NIL & Non-replicating recombination vector; $\mathrm{kan}^{\mathrm{r}}$ & Parish \& Stoker (2000) \\
\hline pGOAL17 & Plasmid carrying $6 \cdot 1 \mathrm{~kb}$ PacI cassette; $\mathrm{kan}^{\mathrm{r}}$ & Parish \& Stoker $(2000)$ \\
\hline pMG24 & p2NIL containing $470 \mathrm{bp}$ unmarked deletion in a $3.5 \mathrm{~kb} d n a \mathrm{~A}$ region; $\mathrm{kan}^{\mathrm{r}}$ & This study \\
\hline pMG25 & $\begin{array}{l}\text { Suicide recombination delivery vector carrying } 470 \mathrm{bp} \text { of an unmarked internal } \\
\text { deletion in } d n a A ; \mathrm{kan}^{\mathrm{r}} \text {; blue }\end{array}$ & This study \\
\hline pMG36 & pMV306 containing M. smegmatis dnaA and its promoter; hyg ${ }^{\mathrm{r}}$ & This study \\
\hline pMG40 & pMV306 containing $d n a A^{\mathrm{Msm}-\mathrm{ttg}} ;$ hyg $^{\mathrm{r}}$ & This study \\
\hline pMG44 & pMV306 containing $d n a A^{\mathrm{Msm}-\mathrm{gtg}} ;$ hyg $^{\mathrm{r}}$ & This study \\
\hline pMBL9 & pMV261 carrying $d n a A$ in antisense orientation; $\operatorname{kan}^{\mathrm{r}}$ & This study \\
\hline
\end{tabular}

proficient E. coli-Mycobacterium shuttle vector (Stover et al., 1993), to create pMG36 (Fig. 1). The integration-proficient vector pMV306 carries attP and int genes derived from the mycobacteriophage L5, and transformation of mycobacteria with this plasmid leads to site-specific integration into the chromosomal attB site (Stover et al., 1993).

$d n a A$ from the ami promoter. The putative promoter region of the amidase gene, amiE, has been shown to be located in the DNA sequence $1.4 \mathrm{~kb}$ upstream of the amidase gene (ami); this region is sufficient to promote inducible ami expression in the presence of acetamide (Parish et al., 1997; Triccas et al., 1998). Hence, the ami promoter region used in the current study included $1.5 \mathrm{~kb}$ of sequence upstream of ami. Oligonucleotides MVM72 and either MVS1 (5'-GCGGATCCATGACTGCTGACCCCGAC) (for amplification of $d n a A$ starting with the codon TTG, referred to as $d n a A^{\mathrm{Msm}-\mathrm{ttg}}$ ) or MVS2 (5'-GCGGATCCATGCTCACTCCGCAGCA-3') (for amplification of $d n a A$ starting with the codon GTG, referred to as $\left.d n a A^{\mathrm{Msm}-\mathrm{gtg}}\right)$ were used to amplify the $\operatorname{dnaA}$ coding region from pMR40 (Rajagopalan et al., 1995). The BamHI recognition sequence, incorporated to facilitate cloning into other vectors, is shown in bold in the primers. DNA fragments digested with $B a m \mathrm{HI}$ were placed under the transcriptional control of the M. smegmatis ami promoter region in pJAM2 (Triccas et al., 1998). The $3 \mathrm{~kb} H i n d I I I-X b a I$ fragment carrying the $1.5 \mathrm{~kb}$ ami promoter and the $d n a A$ coding regions were then cloned into pMV306 to create pMG40 (referred to as $d n a A^{\mathrm{Msm}-\mathrm{ttg}}$ ) and pMG44 (referred to as $d n a A^{\mathrm{Msm}-\mathrm{gtg}}$ ) (Fig. 1).

Construction of non-replicating (suicide) gene replacement vectors. pMR 40, carrying the M. smegmatis dnaA region, was digested with BstBI and the large fragment was self-ligated to make a 470 bp unmarked deletion in $d n a A$. The $3.5 \mathrm{~kb}$ dnaA region was then released by digestion with $B g l \mathrm{II}$ and Pst I and cloned into the BamHI/PstI sites of the vector p2NIL (Parish $\&$ Stoker, 2000) to create pMG24. In the next step, a $6 \cdot 1 \mathrm{~kb}$ PacI marker cassette from pGOAL17 (Parish \& Stoker, 2000) carrying $l a c Z, s a c B$ and $a p h$ was cloned into the PacI site of pMG24 to generate pMG25. This suicide recombination delivery vector was used to disrupt $d n a A$.

Disruption of $d n a A$ and construction of a conditional expression strain. The two-step recombination protocol, followed essentially as described, was used to disrupt $d n a A$ of M. smegmatis (Hinds et al., 1999; Parish \& Stoker, 2000). In the first step, pMG25 was integrated into the $d n a A$ region by homologous recombination, generating a single crossover (SCO) strain that was blue, resistant to kanamycin (kan) and sensitive to sucrose; this strain was designated as RGM15. In the next step, homologous recombination events were selected to identify double crossovers (DCOs) that were white and sensitive to kan but resistant to sucrose. The integrationproficient pMV306-derivative expressing M. smegmatis dnaA (pMG36) from its native promoter was integrated into the attB site of RGM15 SCO to create the merodiploid strain RGM27. Selection for DCOs was then carried out in the same genetic backgrounds. In some experiments, pMG40 integrated in the wild-type background was used; this strain, which was a $d n a A$ merodiploid expressing $d n a A$ from the ami promoter, was designated as RGM35. Similarly, for the construction of a conditional expression strain, $M$. smegmatis $d n a A^{\mathrm{Msm}-\mathrm{ttg}}$ (pMG40) and $d n a A^{\text {Msm-gtg }}$ (pMG44), expressed from the ami promoter, were integrated into the SCO strain RGM15 to generate the merodiploids RGM34 and RGM18, respectively. DCOs were then selected for on agar plates containing $0 \cdot 2 \%$ 

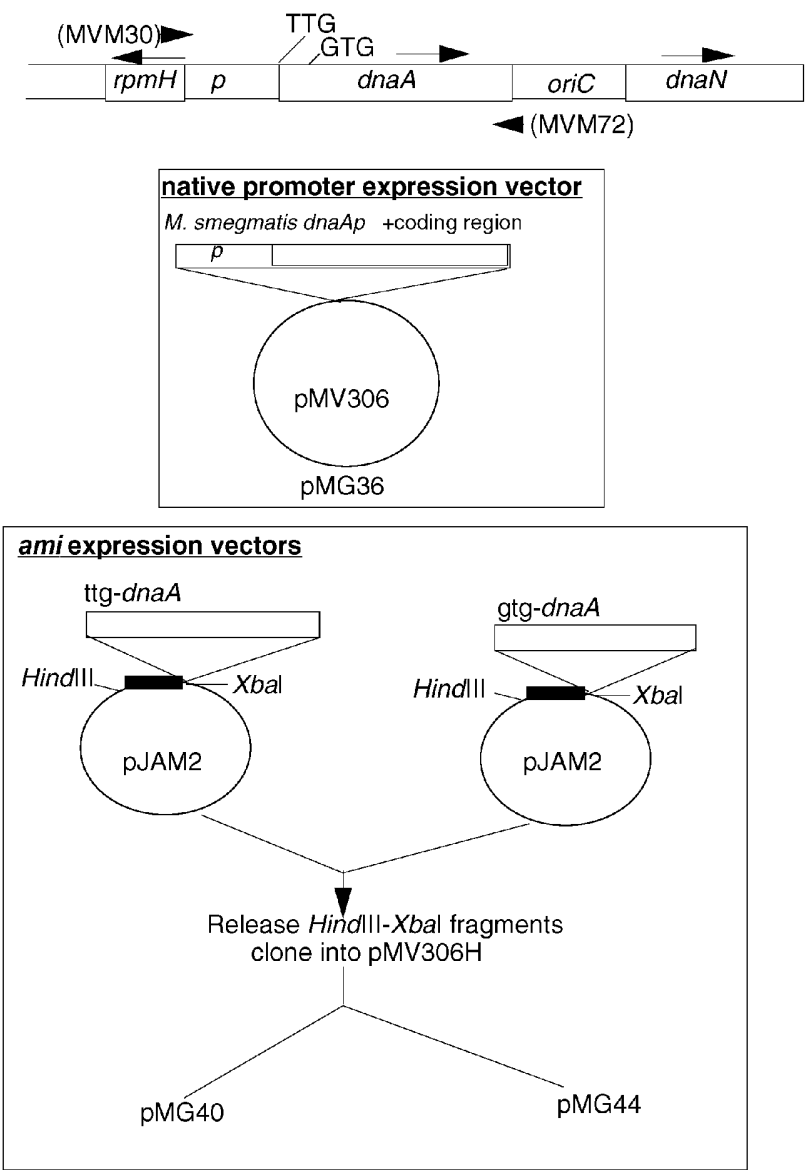

Fig. 1. Construction of $d n a A$ expression vectors. (Upper panels) The $M$. smegmatis $d n a A$ region with the locations of the $r p m H$, $d n a A$, oriC and $d n a N$ genes is shown. The locations of the primers used to obtain different lengths of the $d n a A$ region are shown as arrow heads. The TTG and GTG translational start sites of $d n a A$ are marked. $p$, Putative promoter region of $d n a A$. The PCR fragments obtained using MVM30 and MVM72 were cloned into the $E$. coli-Mycobacterium shuttle vector pMV306 to generate pMG36, which expressed dnaA from its promoter. (Lower panel) Strategies used to construct ami expression vectors are also shown.

acetamide. DCOs were verified by PCR and Southern analyses (Sambrook et al., 1989). One strain, RGM36 (derived from RGM34, which was kan-sensitive, sucrose-resistant, white and expressed $d n a A^{\text {Msm-ttg }}$; Table 1 ), was used in all of the experiments described. This strain was referred to as the conditionally complemented $d n a A$ mutant.

Growth and viability experiments. Unless stated otherwise, all mycobacterial cultures were grown in Middlebrook $7 \mathrm{H} 9$ broth supplemented with albumin/glucose/sodium chloride. The conditionally complemented $d$ naA mutant strain RGM36 was grown in the presence of $0 \cdot 2 \%$ acetamide, washed with acetamide-free medium twice, resuspended in the same medium and then grown for different periods of time, prior to sampling for determinations of DnaA levels by Western blotting and viability by plating, and visualization of cells and nucleoids by microscopy. In the latter case, cells were fixed in $75 \%$ ethanol prior to their visualization by either light or fluorescent microscopy (Dziadek et al., 2002a). The conditionally complemented $d n a A$ mutant strain grown in medium supplemented with acetamide was always used as the control. Growth was followed as the increase in the $\mathrm{OD}_{600}$ value; d.t. was defined as the time required to double the $\mathrm{OD}_{600}$ value. In some experiments, the viability of cultures grown in the absence of acetamide for 6 and 8 d.t. was also determined independently. For determinations of intracellular levels of DnaA, cultures were inoculated to a low cell density $\left(\mathrm{OD}_{600} 0 \cdot 05\right)$ and grown for different periods of time. Cultures harvested at an $\mathrm{OD}_{600}$ value of 0.6 after approximately $24 \mathrm{~h}$ growth were referred to as being in the exponential phase.

Preparation of cellular lysates and Western blotting. Preparation of cellular lysates and Western blotting protocols were followed essentially as described (Dziadek et al., 2002a). Recombinant $M$. tuberculosis DnaA was used to raise polyclonal antibodies in rabbits. The DnaA antibodies were affinity-purified following the protocols described for $M$. tuberculosis FtsZ antibodies (Dziadek et al., 2002a). The extent of cross-reactivity of the $M$. tuberculosis DnaA antibodies with the $M$. smegmatis DnaA antigen is weak as compared to that of the M. tuberculosis counterpart. Nitrocellulose blots were probed with 250 -fold diluted affinitypurified M. tuberculosis DnaA antibodies. Under the experimental conditions used here, the total amount of soluble protein recovered in the clear cell lysates of stationary phase cultures of $M$. smegmatis was less as compared to those of exponential phase cultures, consistent with our earlier results with M. smegmatis and M. tuberculosis cultures (Dziadek et al., 2002b). One reason for the reduced recovery of soluble protein was that the bead-beating-based cell lysis protocols that we used are not optimal for stationary phase cultures, even though these cultures remain viable for the growth period followed. Consequently, DnaA levels were expressed as a percentage of the total soluble protein as determined by using the BCA protein assay kit (Pierce), as opposed to total DnaA molecules per cell. Results are presented as the mean values from three experiments.

Incorporation experiments. DNA synthesis was followed using $\left[5,6-{ }^{3} \mathrm{H}\right]$ uracil essentially as described by Wayne (1977, 1994) and Dick et al. (1998). Wayne (1994) showed that only a negligible amount of thymidine is incorporated into mycobacterial DNA, whereas uracil is not only incorporated into RNA but is also methylated and incorporated into mycobacterial DNA. To permit distinction between DNA and RNA synthesis, duplicate samples of incorporation experiments were incubated for $24 \mathrm{~h}$ at $37^{\circ} \mathrm{C}$ in $0.3 \mathrm{M} \mathrm{KOH}$ before filtering.

Microscopy. Mycobacterial cells were resuspended in buffer A (10 mM Tris/HCl, pH 7.5, $10 \mathrm{mM} \mathrm{MgCl}_{2}$ and $0.02 \%$, v/v, Tween 80), sonicated for $90 \mathrm{~s}$ in a Branson waterbath sonicator to break clumps and then examined either by conventional microscopy or under a Nikon TS 100 inverted microscope with a $100 \times$ Nikon Plan Fluor oil immersion objective with a numerical aperture of 1.3 and working distance of $0 \cdot 17$. The cells were imaged using a Sensicam 12-bit monochromatic CCD camera and SlideBook 3.0 software (3I Imaging). Mycobacterial cells were fixed in $75 \%$ ethanol. Prior to staining, ethanol was removed from the cells by a brief centrifugation and the cells were then washed with buffer A. Cells were stained with a combination of ethidium bromide $\left(40 \mu \mathrm{g} \mathrm{m}^{-1}\right)$ and mithramycin $\left(180 \mu \mathrm{g} \mathrm{ml}^{-1}\right)$, incubated on ice for $30 \mathrm{~min}$ and then photographed, as described previously (Dziadek et al., 2002a). The fluorescence images were acquired using a $100 \mathrm{~W}$ mercury lamp and a Chroma filter set (excitation wavelength $540-565 \mathrm{~nm}$; emission wavelength $560-623 \mathrm{~nm})$. All images were optimized using Adobe Photoshop 5.0. 


\section{RESULTS}

\section{Intracellular levels of DnaA}

If the M. smegmatis DnaA protein is needed for the initiation of DNA replication, we would expect DnaA levels, and possibly activity, to be higher in actively growing cells than in cells in a state of no growth (stationary phase). To evaluate this possibility, DnaA levels in actively growing cells of $M$. smegmatis were measured by Western blotting using anti-M. tuberculosis DnaA antibodies and compared with those in early-stationary (48 h) or late-stationary (96 h) phase cultures. As a control, we measured the levels of FtsZ, a putative initiator of the cell-division process, in the cultures using anti-M. tuberculosis FtsZ antibodies (Dziadek et al., 2002a). DnaA accounted for approxi-

(a)
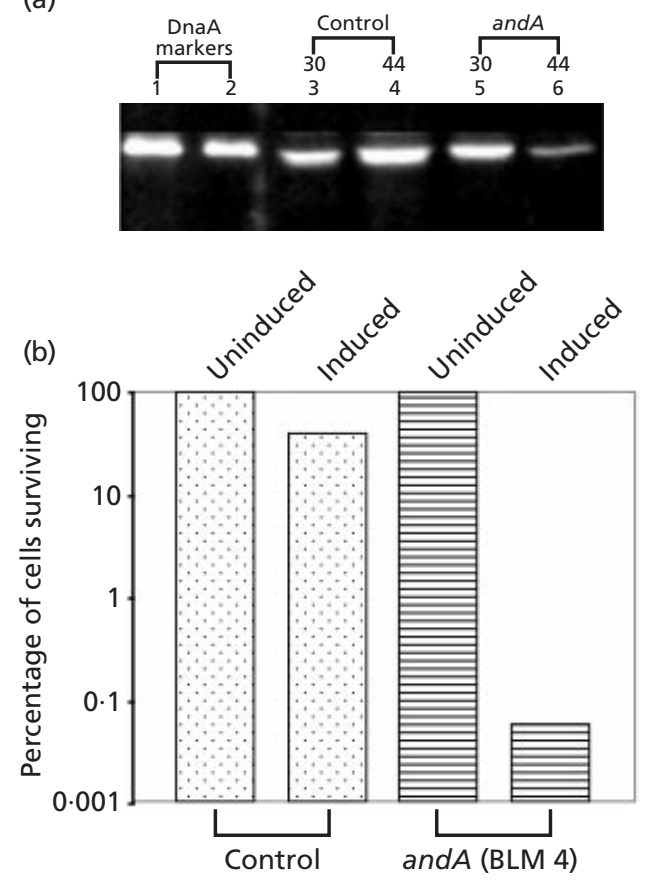

Fig. 2. Effect of dnaA antisense RNA on DnaA levels and cell viability. (a) Western analyses of $M$. smegmatis DnaA. $M$. smegmatis cultures carrying either a control plasmid or antisense construct and $A$ were heat-induced for $2 \mathrm{~h}$ at $44^{\circ} \mathrm{C}$ followed by an additional $3 \mathrm{~h}$ incubation at $37^{\circ} \mathrm{C}$. Cells were harvested, cellular lysates were prepared and approximately $10 \mu \mathrm{g}$ protein from each sample was resolved by SDS-PAGE. Western blotting was performed using anti- $M$. tuberculosis DnaA antibodies. Lanes: 1 and 2, purified recombinant DnaA; 3 and 4, controls; 5 and 6 , antisense construct. Lanes 3 and 5, lysates prepared from cultures grown at $30^{\circ} \mathrm{C}$; lanes 4 and 6 , prepared following heat-induction. (b) Viability of merodiploid cells. Actively growing cultures of $M$. smegmatis expressing dna $A$ antisense RNA or carrying pMV261 were incubated at $30{ }^{\circ} \mathrm{C}$ and then heat-induced for $2 \mathrm{~h}$ at $44{ }^{\circ} \mathrm{C}$. The cultures were then diluted, spread onto Middlebrook agar plates and incubated at $37^{\circ} \mathrm{C}$. Uninduced cultures grown at $30^{\circ} \mathrm{C}$ were diluted, spread onto Middlebrook agar plates and then incubated at $30^{\circ} \mathrm{C}$. The number of surviving cells (expressed as a percentage) was then determined for each sample. mately $0 \cdot 18 \%$ of the total soluble protein in actively growing cells (data not shown); this corresponded to approximately 900-1200 molecules of DnaA per cell. The relatively high levels of DnaA in actively growing cells of $M$. smegmatis were similar to those found for E. coli (Ali Azam et al., 1999). Interestingly, little or no changes in the DnaA levels were noted in stationary phase cultures $(0 \cdot 17 \%$ of total soluble protein), indicating that DnaA levels are maintained at fairly constant levels in both the exponential and stationary phases of growth (data not shown). Under these growth conditions, Fts $Z$ accounted for approximately $1.6 \%$ of the total soluble protein during the exponential growth phase, which corresponded to 10000 molecules of FtsZ per cell, and decreased during the stationary growth phase $(0.9$ and $0.5 \%$ of total soluble protein at 48 and $96 \mathrm{~h}$, respectively).

\section{Expression of $d n a A$ antisense RNA results in inhibition of growth}

If $M$. smegmatis dnaA is essential for cell survival, we would expect that conditions that block the production of $d n a A$ would result in cell death. One approach to decreasing the production of a target protein is to express antisense RNA specific to the gene encoding the protein and then evaluate the consequences associated with the blockage of protein production. To test the above possibility, we constructed a strain expressing $M$. smegmatis dnaA antisense RNA from the heat-inducible $M$. bovis BCG hsp60 promoter and evaluated the consequences of $d n a A$ antisense RNA expression on cell viability. Even though the $h s p 60$ promoter is constitutively active at $30^{\circ} \mathrm{C}$ its activity is elevated at $42{ }^{\circ} \mathrm{C}$ (Stover et al., 1991). Expression of antisense RNA by shifting growth temperatures, i.e. $2 \mathrm{~h}$ at $42{ }^{\circ} \mathrm{C}$ followed by an additional $3 \mathrm{~h}$ growth at $37^{\circ} \mathrm{C}$, significantly reduced the intracellular levels of DnaA (Fig. 2a). Analysis of the bands produced after electrophoresis of the cellular extracts from M. smegmatis using Quantity One software (Bio-Rad) indicated a reduction of approximately $65 \%$ in the amount of DnaA produced under antisense expression conditions. The viability of the cultures carrying the antisense construct decreased significantly at $37^{\circ} \mathrm{C}$ as compared to $30^{\circ} \mathrm{C}$ (Fig. 2b). Taken together, these results indicate that M. smegmatis $d n a A$ is an essential gene for replication and that reductions in the intracellular levels of DnaA decrease viability.

\section{Disruption of $d n a A$}

To further test the essentiality of $d n a A$, we attempted to disrupt the $\operatorname{dna} A$ gene by homologous recombination using the two-step recombination procedure described by Parish \& Stoker (2000). A non-replicating recombination delivery vector containing a 470 bp unmarked internal deletion in the $\operatorname{dna} A$ coding region was constructed (pMG25). The dnaA gene in this construct contained approximately $1.5 \mathrm{~kb}$ of homologous se- 
(a) dnaA region of $M$. smegmatis

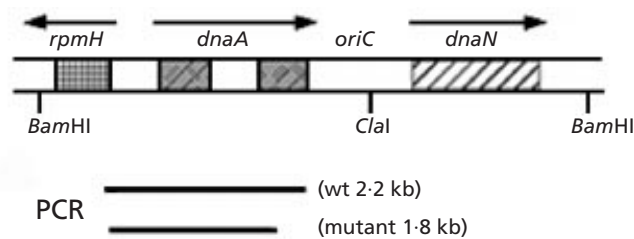

(b)

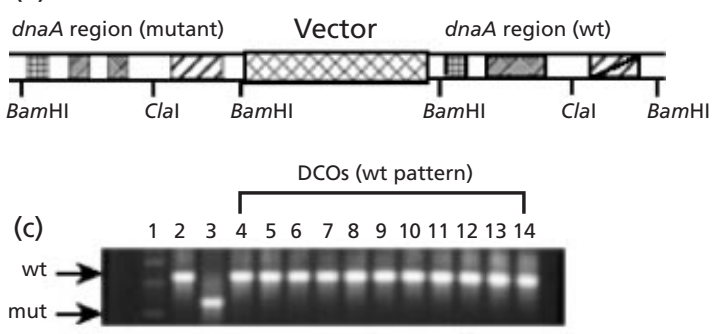

(d)

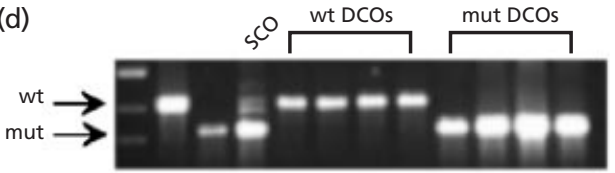

Fig. 3. Disruption of the $M$. smegmatis dnaA gene. (a) The $4 \mathrm{~kb}$ dnaA region of $M$. smegmatis is shown, along with the locations of the $r p m H, d n a A$ and $d n a N$ genes (hatched boxes); the direction of transcription for each of the genes is indicated by an arrow. The location of oriC is also shown. The open box within dnaA indicates the $470 \mathrm{bp}$ deletion. Restriction sites are also shown. The expected PCR amplification products for the wild-type (wt) and mutant are marked. (b) Genetic organization of the dnaA SCO strain RGM15. Southern analysis confirmed the presence of both copies of the $d n a A$ region within the strain. The site of integration is upstream of $r p m H$. (c) Analysis of DCOs by PCR. Genomic DNA was prepared from each of the 80 kan-sensitive, sucrose-resistant white DCOs and analysed by PCR (lanes 4-14; although not shown, the patterns of other DCOs are similar). Lanes: 1, marker; 2, amplification product obtained from wild-type cells; 3 , amplification product obtained using pMG25. wt, Wild-type; mut, mutant. (d) Analysis of DCOs generated from the merodiploid strain. Genomic DNA from the DCOs obtained in the RGM27 merodiploid background was amplified with oligonucleotide primers targeted to $d n a A$ and oriC. The products obtained were verified by agarose gel electrophoresis. DNA bands corresponding to the amplification products from the wt $(2.2 \mathrm{~kb})$, the mut $(1.8 \mathrm{~kb})$ and the SCO strains $(2.2$ and $1.8 \mathrm{~kb}$ bands, although the $1.8 \mathrm{~kb}$ band was preferentially amplified) are shown. wt DCOs and mutant DCOs are shown.

quence on each side flanking the deletion (Fig. 3a). The vector also carried positive $(a p h)$ and negative $(\operatorname{sac} B)$ counterselectable markers as well as lac $Z$ for screening. Electroporation of M. smegmatis with pMG25 produced several SCO transformants that were blue and resistant to kan but sensitive to sucrose. One SCO strain, RGM15 (Fig. 3b), was used to isolate further homologous recombination events, and DCOs that were white, resistant to sucrose and sensitive to kan were identified. Since recombination could occur on either side of the deletion, DCOs could contain either the wild-type or the deleted allele. To test if any of the DCOs had the mutant
dnaA gene, genomic DNA from 80 DCOs was prepared; the DNA fragment containing the dnaA promoter and its gene was amplified by PCR using primers targeted at the $5^{\prime}$ end of the promoter (MVM30) and at the $3^{\prime}$ end of dnaA (MVM72). Analysis of the sizes of the amplified products from the 80 DCOs identified the presence of DNA fragments corresponding to the intact $d n a A$ gene, like the M. smegmatis wild-type strain (Fig. 3c), indicating that homologous recombination in the $d n a A$ region was yielding only the wildtype pattern. Southern analyses confirmed these results (data not shown). The absence of any $d n a A$ mutants suggested that $d n a A$ is an essential gene in M. smegmatis.

To establish the essentiality of $d n a A$, a second functional copy of $d n a A$ that included its own putative promoter was cloned into an L5-based integration vector, pMV306, to create pMG36; pMG36 was then integrated at the att locus of RGM15. The site of integration of pMG36 at the att locus was confirmed by Southern analysis (data not shown); subsequently, one merodiploid, designated RGM27, was used to select DCOs as described above. PCR analyses of 10 of the DCOs revealed both wild-type and mutant patterns (in a ratio of $6: 4$ ) (Fig. 3d), indicating that $d n a A$ can be disrupted at its native locus provided a functional copy of the same gene is supplied elsewhere on the genome. Southern analyses confirmed these findings (data not shown). The relative frequency of recombination that gave rise to the disrupted allele of $d n a A$ at its native locus was very high $(40 \%)$. If $d n a A$ was not essential, we would have detected mutant DCOs in approximately 32 of the 80 DCOs (Fig. 3c). Thus, the failure to obtain any mutant $d n a A$ alleles in the wild-type background using the same recombination substrates used in the $d n a A$ merodiploid background clearly indicates that $d n a A$ is essential in M. smegmatis ( $p<0 \cdot 0003$, using Fisher's exact test).

\section{Conditional expression of $d n a A$}

To gain insights into the roles of $d n a A$ in DNA replication, we constructed a $d n a A$ conditional expression strain by placing the coding region of $d n a A$ under the transcriptional and translational control of the ami promoter region (Parish et al., 1997; Triccas et al., 1998). The M. smegmatis ami promoter is one of the best characterized regulatable promoters in mycobacteria and its promoter activity can be induced by the addition of acetamide to the growth medium (Parish $e t$ al., 1997; Triccas et al., 1998). Two potential translational start sites for $M$. smegmatis dnaA have been proposed - one starting with GTG (Rajagopalan et al., 1995) and another starting with TTG, which is located 90 codons upstream of the predicted GTG start codon (Salazar et al., 1996). The $d n a A$ coding regions starting with the GTG $\left(d n a A^{\mathrm{Msm}-\mathrm{gtg}}\right)$ and TTG $\left(d n a A^{\mathrm{Msm}-\mathrm{ttg}}\right)$ initiation codons were cloned individually into pMV306 (see Methods) to create a translational fusion with the first six amino acids of the product of amiE (Triccas et al., 1998). The resulting recombinant plasmids were integrated into the RGM15 SCO strain and their sites of 

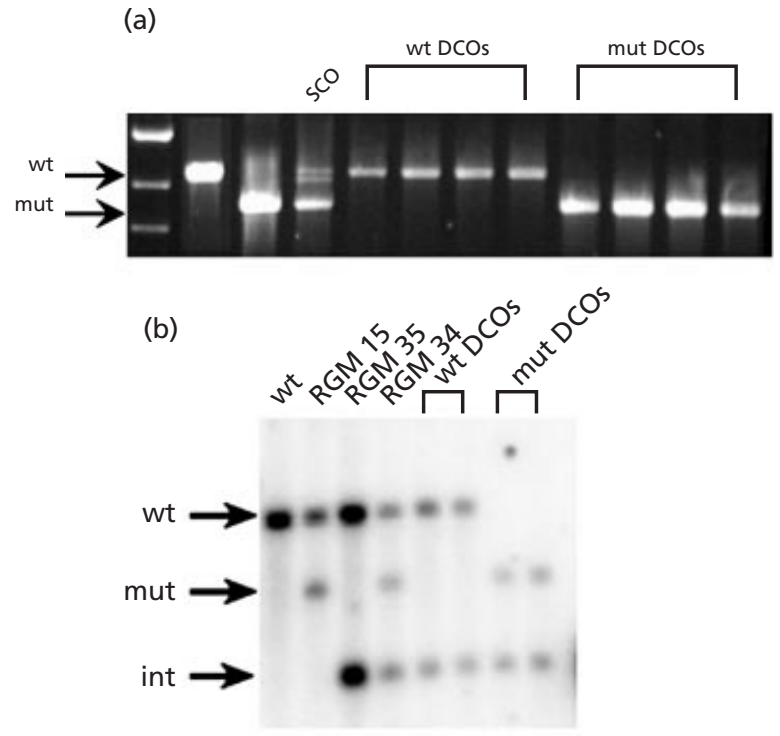

Fig. 4. $P C R$ and Southern analyses of DCOs generated from the merodiploid expressing $d n a A$ from the ami promoter. (a) Agarose gel analysis of the PCR products. All amplification conditions are as described for Fig. 2(d). wt, Wild-type; mut, mutant. (b) Southern analysis of the DCOs. Genomic DNA extracted from the different mycobacterial strains was digested with $\mathrm{BamHI} / \mathrm{Clal}$; the $1.5 \mathrm{~kb} d n a A$ gene was used as a probe. Arrows corresponding to wt, mut and SCO copies of the dnaA gene are shown to the left; genotypes of the strains used are shown at the top of the image.

integration were verified by PCR; DCOs were selected as described earlier. To enable a continuous supply of DnaA, DCOs were selected on agar plates containing acetamide. The concentration of acetamide used elevated the intracellular levels of DnaA by approximately sixfold (see below), but it was not toxic to the cells as it did not interfere with their growth or viability (see below). Analyses of 10 DCOs obtained with the dna ${ }^{\text {Msm-ttg }}$ construct, by PCR (Fig. 4a) and Southern blotting (Fig. 4b), confirmed the presence of mutant and wild-type $d n a A$ patterns in a ratio of $4: 6$. One mutant DCO, designated RGM36, was characterized further. In contrast to the DCOs obtained with the $d_{n a} A^{\text {MsM-ttg }}$ construct, all 80 DCOs obtained with the $d_{n a} A^{\mathrm{Msm}-\mathrm{gtg}}$ construct revealed only the wild-type pattern, indicating that the truncated DnaA protein produced from the $d n a A^{\text {Msm-gtg }}$ construct was non-functional.

\section{Depletion of DnaA levels and cell viability}

To test the consequences of blocked dnaA expression on the viability of $M$. smegmatis, the conditionally complemented dnaA mutant strain RGM36 was grown in the presence of acetamide, washed, resuspended in Middlebrook 7H9 medium, spread onto plates with and without acetamide and then incubated at $37^{\circ} \mathrm{C}$. Determinations of the numbers of RGM36 cells on the acetamide-free plates revealed a nearly $5 \log$ reduction in cell viability as compared to the number of RGM36 cells observed on acetamide-containing plates, which grew at

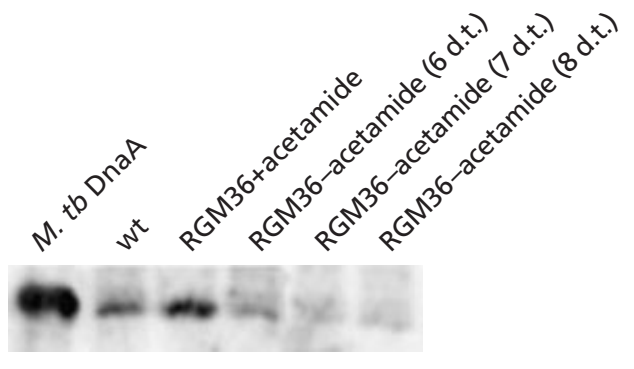

Fig. 5. Western analysis of the strain conditionally expressing dnaA, RGM36. An actively growing culture of RGM36 grown in the presence of $0.2 \%$ acetamide was washed, resuspended to low cell density $\left(O D_{600} 0.01\right)$ and then grown in the absence of acetamide for different periods of time. Cultures were harvested at different periods of time, from which lysates were prepared and analysed by Western blotting using anti- $M$. tuberculosis DnaA antibodies. As a control, a cell lysate prepared from wild-type (wt) $M$. smegmatis was also used. Purified recombinant $M$. tuberculosis DnaA ( $M$. tb DnaA) was used as a marker.

levels comparable to those of wild-type cells (control) (data not shown). The colonies growing on the acetamide-free plates were very small and appeared slowly as compared to the wild-type control and the cultures grown on the acetamide-containing plates. Presumably, withdrawal of acetamide from the medium resulted in a depletion in the intracellular levels of DnaA and decreased cell viability. The RGM36 cells that grew on the acetamide-free plates appeared to have accumulated mutations, because these cells continued to grow, like the controls, when they were resuspended in fresh medium that lacked acetamide.

We also noted that the appearance of colonies of RGM36 and of the dnaA merodiploid (RGM35) on acetamide plates was delayed, when compared to the wild-type control (M. smegmatis). Presumably, this delay was due to cell lengthening and the loss of synchrony between DNA replication and cell-division events (see below). Western analyses confirmed a gradual depletion in the DnaA levels in RGM36 cells that had been grown in the absence of the inducer, acetamide (Fig. 5b). Analyses of the bands produced by Western blotting, using the QUANTITY ONE software (Bio-Rad), indicated that parent RGM36 cells grown in the presence of acetamide had approximately sixfold higher levels of DnaA compared to the wild-type cells, whereas RGM36 cells starved of acetamide had significantly depleted levels of DnaA, i.e. they were reduced by half at 6 d.t. and nearly undetectable at 7 and 8 d.t. (data not shown).

\section{Blocked dnaA expression selectively and specifically blocks DNA replication}

If $M$. smegmatis DnaA is critical for the initiation of DNA replication, cells depleted of DnaA would be defective for re-initiation and, consequently, would not be proficient in DNA synthesis. To test this prediction, RGM36 cells grown in the presence of acetamide were 

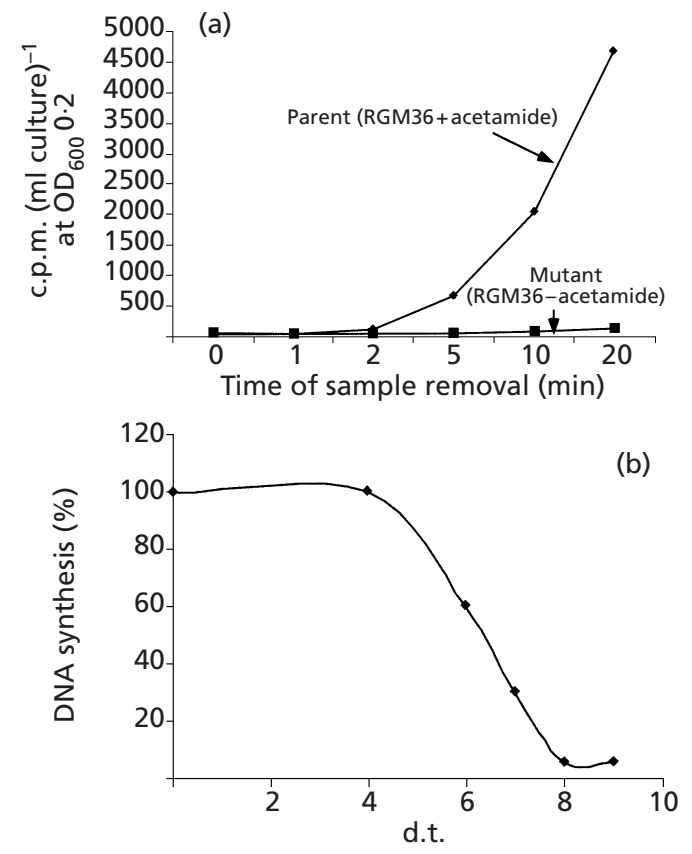

Fig. 6. DNA synthesis in DnaA-depleted cells. (a) Kinetics of DNA synthesis in RGM36 cells. Actively growing cultures of RGM36 grown in the presence of acetamide were washed, diluted to low cell density, resuspended in broth with and without acetamide and then grown for several d.t. Cultures were harvested at the time period corresponding to 8 d.t., diluted and then mixed with tritium-labelled 6-methyluracil. Samples were removed at various time points and processed for the determination of the radioactivity incorporated into the DNA (Wayne, 1977, 1994). The viability of the acetamidestarved cells at 8 d.t. was comparable to that of cells grown in the presence of acetamide (data not shown). (b) DNA synthesis as a function of acetamide starvation. RGM36 cultures growing in the absence of acetamide for different d.t. were removed and DNA synthesis was measured $20 \mathrm{~min}$ after the addition of the radioactivity to the culture.

washed, resuspended to low cell density in acetamidefree medium and then grown for a period corresponding to 8 d.t. The ability of the cultures to synthesize DNA was then examined (Wayne, 1977, 1994). As can be seen in Fig. 6(a), cells starved of acetamide (and therefore lacking in DnaA production) were nearly deficient in DNA synthesis, whereas those grown in the presence of acetamide were proficient in DNA synthesis, incorporating radioactivity in an exponential manner. The viability of the cultures starved of acetamide, i.e. for 8 d.t. of growth, was comparable to the viability of the RGM36 cells grown in the presence of acetamide (data not shown). To determine how rapidly DNA synthesis in RGM36 cells was stopped, cells starved of acetamide for different periods of time were tested for their ability to synthesize DNA. As can be seen in Fig. 6(b), DNA synthesis continued to proceed up to a period corresponding to 4 d.t., after which time it steadily declined, and it was nearly completely abolished after 8 d.t. Western analysis indicated that DnaA levels were significantly reduced at 6 d.t. and nearly undetectable at 7 and 8 d.t. in the cells starved of acetamide (Fig. 5).

\section{Cells producing altered levels of DnaA are filamentous and multinucleoidal}

DNA replication leads to cell division that results in the duplication of cells, and these two processes are believed to be synchronized (Donachie, 1993; Zyskind \& Smith, 1992). Assuming that M. smegmatis DnaA is required for the initiation of DNA replication, cells inhibited in DnaA production should not initiate new rounds of replication but should complete the current round of DNA synthesis and subsequently divide, thereby resulting in a single nucleoid state [Cook \& Rothfield (1999) and Sun \& Margolin (2001), and references therein]. To test this possibility, RGM36 cells starved of acetamide were examined by light microscopy and compared to RGM36 cells grown with acetamide and also to wildtype M. smegmatis cells. To visualize their nucleoids, the cells were stained with DNA-specific dyes, e.g. propidium iodide or an ethidium bromide/mithramycin combination, and examined by fluorescence microscopy as described previously (Dziadek et al., 2002a) (Fig. 7). As expected, the wild-type $M$. smegmatis cells were small (Fig. 7b) and were characterized by the presence of one nucleoid per dividing cell (Fig. 7a). No differences in the cell morphology of the M. smegmatis cultures grown in the presence and absence of acetamide were noted, indicating that acetamide per se has no effect on cell morphology (data not shown). In contrast to these findings, RGM36 cells grown in the presence of acetamide were at least two to three times longer than the wild-type cells (Fig. 7h); these elongated cells are referred to as short filaments. DNA staining revealed the presence of several distinct, well-separated nucleoids in the short filaments (Fig. 7g). Cell lengthening was due to DnaA overproduction, since in the absence of acetamide, i.e. under uninduced conditions, the $d n a A$ merodiploid cells expressing ami-dnaA (RGM35) were small (Fig. $7 \mathrm{~d})$, like the wild-type controls, and contained one or two nucleoids per cell (Fig. 7c); however, under induced conditions the RGM35 cells were elongated (Fig. 7f) and multinucleoidal (Fig. 7e). The viabilities of the dnaA merodiploid cells (RGM35) and the conditionally complemented dnaA mutant cells (RGM36) grown in the presence of acetamide were similar to their wild-type controls (data not shown), suggesting that these cells do eventually complete cell division. From these data, we infer that cell division is delayed in DnaA-overproducing cells. Presumably, DNA replication and cell-division processes are not coordinated under elevated DnaAoverproducing conditions.

The RGM36 cells starved of acetamide were extremely filamentous (Fig. 7j, l), with mean cell lengths four to five times those of the parent cells grown in the presence of acetamide (data not shown). Notably, the majority of the cells examined contained either several distinct, well-separated nucleoids (Fig. 7i, k) or abnormal nucleoids (Fig. 7i, m). We classified nucleoids as abnormal when we could not distinguish distinct nucleoids. Many of the filamentous cells contained large regions of nucleoid-free zones (arrows in Fig. 7i, m). The presence of large chromosome-free areas in the filamentous cells 

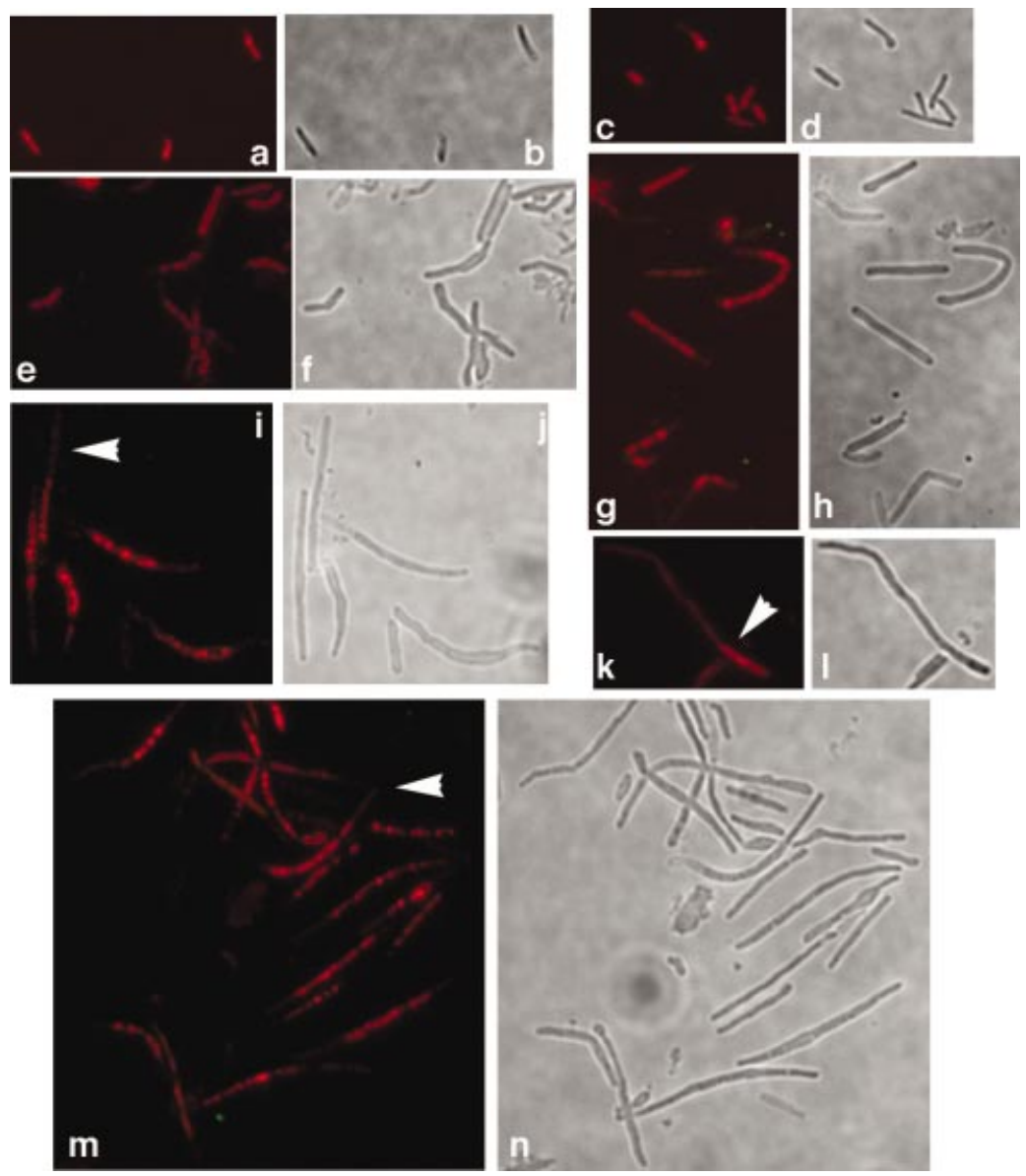

Fig. 7. Visualization of cells and nucleoids of the different mycobacterial strains. Actively growing cultures of the different mycobacterial strains were fixed in $70 \%$ ethanol, prior to visualization of their cells and nucleoids. Cells were stained with ethidium bromide/mithramycin for $15 \mathrm{~min}$ and then visualized under a fluorescent microscope. For each culture condition, phase-contrast images (b, d, f, h, j, l, n) and nucleoid staining (a, c, e, g, i, k, m) are shown. Although not shown, cell-length measurements indicated that the RGM36 acetamide-starved cells were three to four times the size of their parent cells. (a, b) Wild-type $M$. smegmatis control. (c-f) dnaA merodiploid strain RGM35; (c, d) uninduced cells grown in the absence of acetamide; $(e, f)$ induced cells grown in the presence of acetamide. $(g-n)$ Conditionally complemented dnaA mutant strain RGM36; $(\mathrm{g}, \mathrm{h})$ cultures grown in the presence of acetamide; (i-n) cultures starved of acetamide. indicated replication arrest. In some cells, nucleoids were present close to a pole (Fig. 7k), centrally (Fig. 7i, $\mathrm{m}$ ) or along the entire length of the cell, but it was not clear whether these cells would continue to increase in size (Fig. $7 \mathrm{~m}$ ). Acetamide-starved RGM36 cells showed linear growth, whereas those grown in the presence of acetamide showed exponential growth (data not shown). In the above experiments, acetamide-starved cells that corresponded to 8 d.t. of growth in acetamidefree medium were examined. We also noted that a small number of the cells corresponding to 6 d.t. of growth in acetamide-free medium were filamentous, whereas those corresponding to 4 d.t. of growth in the same medium looked like their parents (i.e. short filaments; data not shown). Since these cells continued to synthesize DNA (Fig. 6), it appears that the filament length increased only after blockage of DNA synthesis occurred. These results are consistent with the notion that replication of the filamentous cells is blocked at the cell-division stage.

\section{DnaA-depleted cells recover and multiply following the addition of acetamide}

To determine whether cells depleted in DnaA would recover and divide, acetamide was added to RGM36 cells that had been starved of acetamide for $36 \mathrm{~h}$ of growth. The viability and cell morphology of these cultures were then examined. The viability of the acetamide-replenished cultures was restored to levels comparable to those of the RGM36 cells grown in the presence of acetamide (data not shown). Importantly, the lengths of the filament cells decreased, and were comparable to those of the RGM36 cells grown in the presence of acetamide (Fig. $8 \mathrm{~b}, \mathrm{~d}$ ). Furthermore, the short filaments also contained distinct, well-separated nucleoids (Fig. 8a, c). No visible DNA-less cells were detected under these conditions. The appearance of colonies on agar plates was delayed by approximately 24-36 h, and the colonies were heterogeneous upon their appearance (data not shown). Presumably, the delayed appearance of the colonies was due to the slow accumulation of DnaA to sufficient levels for subsequent resumption of cell division, prior to the initiation of new rounds of cell-cycle events.

\section{Cells producing $d n a A$ antisense RNA contain more than one nucleoid}

The multinucleoidal state of the acetamide-starved cells (Fig. $7 \mathrm{i}, \mathrm{k}, \mathrm{m}$ ) could have been due to the fact that the parent RGM36 cells grown in the presence of acetamide were multinucleoidal (Fig. $7 \mathrm{~g}$ ). Hence, we attempted to determine the nucleoid state of cells following depletion of DnaA, starting with a non-DnaA-overproducing cell population. Accordingly, we characterized BLM4 merodiploids expressing antisense $d n a A$ RNA by microscopy 

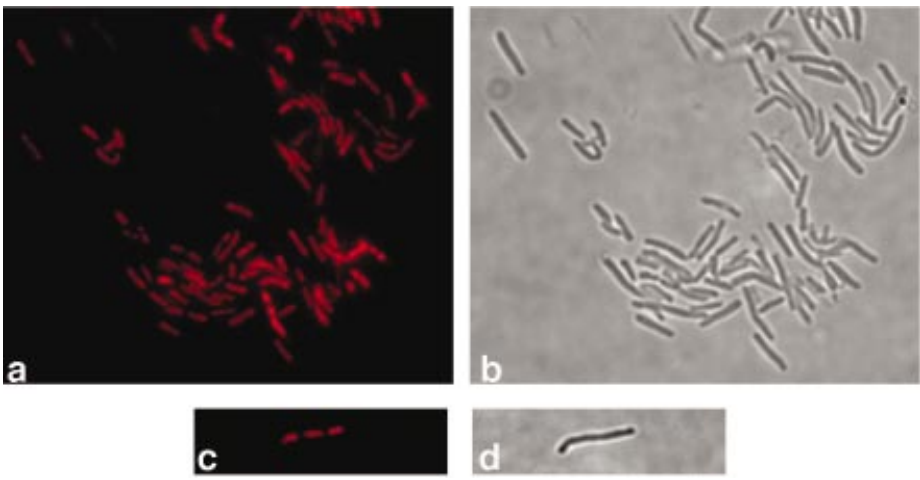

Fig. 8. Reversal of the DnaA depletion phenotype. Acetamide-starved RGM36 cells were grown in the presence of $0.2 \%$ acetamide for $20 \mathrm{~h}$, prior to visualization of their cells and nucleoids by microscopy (as described in Fig. 7). ( $a, c)$ DNA-stained cells; (b, d) phase-contrast images of the cells shown in (a) and (c). (a)

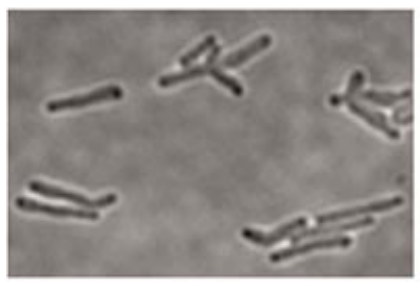

(b)

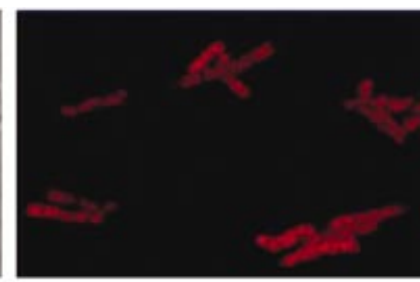

Uninduced

(c)

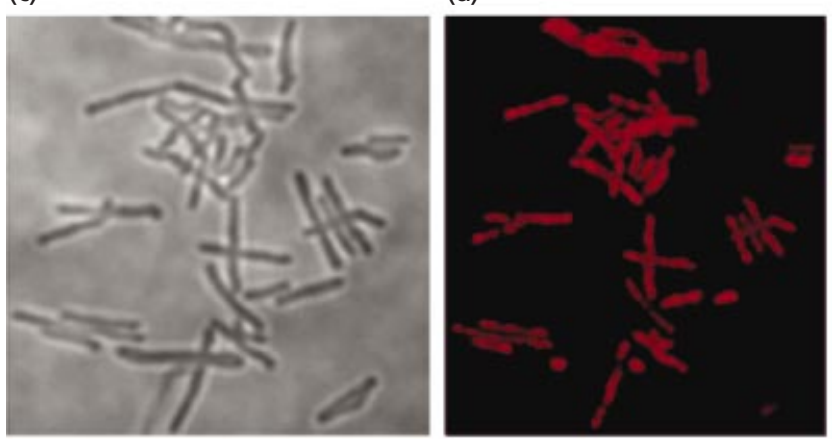

Induced

Fig. 9. Visualization of cells and nucleoids of BLM4. Merodiploid cells expressing $d n a A$ antisense RNA were examined as described in Fig. 7. Cultures grown at $30^{\circ} \mathrm{C}$ are referred to as 'uninduced', whereas those that were heatinduced for $2 \mathrm{~h}$ at $42^{\circ} \mathrm{C}$ followed by growth at $37^{\circ} \mathrm{C}$ are referred to as 'induced'. (a, c) Phase-contrast images of the cells shown in (b) and (d); (b, d) DNA-stained cells.

(Fig. 9). Two observations could be made. First, the BLM4 cells grown under uninduced conditions contained between two and four nucleoids (Fig. 9a, b), unlike the control cells (Fig. 6a, b). It should be noted that the $\operatorname{dnaA}$ antisense RNA was made from a constitutively active $M$. bovis BCG hsp65 promoter. Although we did not detect any major changes in the levels of DnaA present under uninduced conditions as compared to the control (Fig. 2a), the constitutive levels of antisense $d n a A$ RNA produced might have been sufficient to affect nucleoid distribution in the cell. Second, BLM4 cells grown under induced conditions were more elongated than the uninduced cells and were multinucleoidal (Fig. 9c, d). However, continued growth at $37^{\circ} \mathrm{C}$ did not increase the length of these cells (data not shown), similar to the situation seen with the acetamide-starved cells (Fig. 7i, k, m). Cell-length measurements revealed that the majority (nearly $86 \%$ ) of the uninduced cells were between 1 and $1.8 \mu \mathrm{m}$ in length; in contrast, the majority of the induced cells were elongated and approximately $55 \%$ of these cells were more than $2.0 \mu \mathrm{m}$ in length. With the acetamidestarved cells, we found that the cell length increased only after complete depletion of DnaA and inhibition of DNA synthesis. Presumably, the antisense effect under induced conditions is not complete, thereby allowing some $d n a A$ expression and subsequent protein accumulation; hence, this could explain the short filament length of the uninduced cells.

\section{DISCUSSION}

Genetic studies on the genes involved in the initiation of DNA replication in mycobacteria are lacking; hence, this study focuses on one of the important proteins believed to be involved in the replication initiation process in M. smegmatis, namely DnaA. In the present study, we uncoupled $M$. smegmatis dnaA transcription from its native promoter and expressed $d n a A$ under the transcriptional control of the acetamide-inducible ami promoter region (Triccas et al., 1998). We showed that withdrawal of acetamide from the growth medium led to a depletion of the intracellular levels of DnaA, which resulted in inhibition of DNA synthesis and reduced cell viability. These results, combined with biochemical data showing specific binding of the recombinant $M$. $t u$ berculosis DnaA protein to oriC (Yamamoto et al., 2002) and to DnaA boxes (Dziadek et al., 2002b), suggest a role for mycobacterial DnaA in the initiation of DNA replication.

The intracellular levels of $M$. smegmatis DnaA were found to be constant during the exponential and stationary phases of growth (data not shown). In contrast, we found that the intracellular levels of FtsZ (a putative initiator protein of the cell-division process in mycobacteria) were growth-phase dependent, suggesting that Fts $Z$ is required in actively dividing cells. The relatively high and stable intracellular levels of DnaA present in $M$. smegmatis suggest a continued 
requirement for this protein in cell metabolism. DnaA is believed to function as a transcriptional regulator of many genes, including itself in E. coli (Messer et al., 1988; Messer \& Weigel, 1997). The binding of E. coli DnaA to DnaA boxes located in the promoter regions of $d n a A$ and polA has been shown to result in transcriptional repression (Atlung et al., 1984, 1985; Braun et al., 1985 ; Braun \& Wright, 1986; Polaczek \& Wright, 1990; Skovgaard et al., 1998; Smith et al., 1997). Scanning the putative promoter regions of several genes, including, for example, dnaA, fts $Y$ and $f t s Q$ of $M$. smegmatis (Institute of Genome Research; http://www.tigr.org/) and M. tuberculosis (Cole et al., 1998), revealed the presence of several nine nucleotide long sequences with one to two mismatches to the conserved DnaA box sequence TTCA/GGCACA (Madiraju et al., 1999; Qin et al., 1999; Rajagopalan et al., 1995). Thus, the possibility that the fairly constant levels of DnaA present in vivo are needed to bind to the putative DnaA boxes located in the promoter region, for subsequent transcriptional repression of some unknown target genes, cannot be ruled out.

DNA synthesis experiments clearly indicated that depletion of DnaA leads to the inhibition of DNA synthesis (Fig. 6). It is pertinent to note that nearly complete inhibition of DNA synthesis occurred only after acetamide starvation for periods corresponding to $7-8$ d.t. This result is different from those observed with other bacterial dnaA conditional mutants, where blockage of DNA synthesis has been shown to occur after approximately 1 d.t. (Gorbatyuk \& Marczynski, 2001). In the present study, conditional $d n a A$ expression was attained from the acetamide-regulatable ami promoter. Thus, one explanation for our observations is that the ami promoter could be leaky, thereby enabling a slow but continuous accumulation of DnaA. In support of this assumption, we have recently found that the expression of $f t s Z-g f p$ (the gene for a green fluorescent fusion protein of FtsZ) from the ami promoter in M. smegmatis hosts is leaky under uninduced conditions (J. Dziadek, M.V.V.S. Madiraju \& M. Rajagopalan, unpublished data). Thus, elevated levels of DnaA in RGM36 cells grown in the presence of acetamide (Fig. 4b) combined with a leaky expression of $d n a A$, if any, could lead to a gradual (but not abrupt) decrease in the intracellular pools of DnaA, leading to a slow and continued synthesis of DNA under acetamide-starved conditions. Alternatively, slow but continuous DNA synthesis under acetamide-starved conditions (Fig. 6; near normal levels of synthesis up to 4 d.t. and slow but continuous synthesis up to 6 d.t.) could be due to a prolonged replication period. The elevated levels of DnaA in RGM36 parent cells could promote overinitiation at oriC, resulting in multiple replication forks that proceed slowly to bidirectional replication, thereby resulting in an overall increase in DNA content. Thus, a prolonged replication period during overproduction of DnaA could have led to the multinucleoidal state. Detailed determinations of the DNA contents of cells and the originto-terminus ratios produced under altered DnaA levels could provide clues as to the changes in the replication period, if any. Another possibility, which is speculative at the moment, is that M. smegmatis contains a hitherto unidentified gene that is paralogous to $d n a A$ and has some residual $d n a A$ activity. These possibilities are not mutually exclusive and further studies are required to address these issues.

The bacterial cell cycle is divided into two parts: a replication cycle, which includes both chromosomal replication and partitioning of DNA, and a division cycle. Both processes are believed to be linked, and defects in either of these processes lead to filamentation of the cell (Cook \& Rothfield, 1999; Sun \& Margolin, 2001). Consistent with this assumption are reports showing that either overproduction of FtsZ, a putative initiator of cell division (Dziadek et al., 2002a), inactivation of WhmD, a putative cell-division protein (Gomez \& Bishai, 2000), or thermal inactivation of DnaG primase, required for DNA-chain elongation (Klann et al., 1998), lead to filamentation in $M$. smegmatis. Similar to these results, we noted that alterations in DnaA levels, i.e. either increases or decreases, resulted in cell lengthening, although DnaAdepleted cells were much more filamentous than DnaAoverproducing cells (compare Fig. $7 \mathrm{j}, \mathrm{l}, \mathrm{n}$ with $\mathrm{f}$ ). Interestingly, the filamentous cells contained several distinct, well-separated nucleoids under overproduction and depletion conditions. The major difference between the two conditions was that filamentation due to depletion of DnaA was associated with a severe loss of cell viability. In contrast, filamentous cells produced after exposure to DnaA-overproduction conditions continued to grow without any decrease in viability (Fig. 5). These results tend to indicate a loss of coordination between the DNA replication and cell-division events under altered levels of DnaA.

Our results showing the multinucleoidal state in filamentous cells under DnaA-depleted conditions are somewhat unexpected. Cell division is expected to proceed to completion in $d n a A$ mutants, thereby resulting in cells containing a single nucleoid (Cook \& Rothfield, 1999; Sun \& Margolin, 2001). Obviously, this was not the case with the acetamide-starved cells of $M$. smegmatis, thus signalling a correlation between the initiation of DNA replication and cell-division events in this organism, and that DnaA may have a role in these two events.

How can we explain the multinucleoidal state of cells under altered DnaA production conditions? The conditionally complemented $d n a A$ mutant cells (RGM36) grown in the presence of acetamide had elevated levels of DnaA (Fig. 5b) and were multinucleoidal, although these cells continued to grow without any reduction in their viability. Presumably, cell lengthening and the multinucleoidal state of the DnaA-overproducing cells are due to induction of an SOS-like response. It is conceivable that either the activity or the level(s) of protein(s) responsible for cell division in M. smegmatis could be sensitive to the intracellular levels of DnaA, and this might be one way by which $M$. smegmatis 
tightly coordinates its DNA replication with its cell division. DnaA could exert such an effect directly either by binding to the presumptive DnaA boxes located in the promoter regions of target genes or by interacting with the proteins, or indirectly by recruiting other protein(s). It is worth noting that the filamentous and multinucleoidal state observed under DnaA-overproduction conditions is reminiscent of the B. subtilis yabA mutant phenotype (Noirot-Gros et al., 2002). The yabA gene product has been implicated in the negative regulation of $B$. subtilis replication. Thus, the possibility that alterations in the activity and/or the levels of the putative negative regulators of $M$. smegmatis DNA replication under elevated DnaA production conditions remains open.

Similarly, growth in the absence of acetamide, which led to a gradual depletion in the levels of DnaA and DNA synthesis (Figs 5 and 6), also resulted in the multinucleoid state. In this scenario, the residual levels of DnaA in acetamide-starved cells may be sufficient to trigger new rounds of replication that proceed to completion, thereby resulting in the multinucleoidal state, but not sufficient to coordinate DNA replication with cell-division events. This could lead to a blockage in cell division, again signalling a linkage between DNA replication and cell-division events. Our results showing the polynucleoidal state of merodiploid cells expressing antisense dnaA RNA are somewhat surprising (Fig. 9). With a non-DnaA-overproducing cell population we thought that induction of $d n a A$ antisense RNA would ultimately produce elongated cells with a single nucleoid, but this was not the case (Fig. 9d). Presumably, constitutive levels of $d n a A$ RNA expression under uninduced conditions were sufficient to affect the septation process, thereby resulting in the multinucleoidal state. Currently, our studies are limited by the number of available regulatory promoters known to affect gene expression in mycobacteria; hence, we are unable to ascertain the effect(s) of $d n a A$ expression on septation at this time. The expression of $d n a A$ antisense RNA from tight, inducible promoters that eliminate background expression could produce a starting population of cells that contain a single nucleoid. It should be noted that antisense expression under induced conditions, although effective in reducing intracellular DnaA levels (Fig. 2a), is not totally leak-proof. This could in turn lead to a slow but steady accumulation of DnaA; hence, an increase in the cell length under induced conditions $\left(42{ }^{\circ} \mathrm{C}\right.$ for $2 \mathrm{~h}$ followed by continued growth at $37^{\circ} \mathrm{C}$ ) comparable to that observed with the acetamide-starved cells was not observed (Fig. 7i, m, n).

It is pertinent to note that the overproduction of $B$. subtilis DnaA has been shown to induce cell lengthening but, unlike the results reported in the present study, this lengthening resulted in inhibition of cell growth (Ogura et al., 2001). Increasing the intracellular levels of DnaN in the DnaA-overproducing cells restored them to a wild-type phenotype. In our experiments, approximately sixfold DnaA overproduction was attained under acetamide growth conditions (Fig. 5b). It is not known whether we can attain more than sixfold DnaA overproduction in cells and, if so, whether this would result in growth inhibition. Further characterization of the roles of DnaA in DNA replication and cell-cycle events will enable us to understand why and at what stage DnaA-overproducing cells are arrested in cell division and how these replication processes are related to those of B. subtilis and E. coli.

\section{ACKNOWLEDGEMENTS}

We thank Drs Cliff Barry, II and William R. Bishai for mycobacterial plasmids, Dr William R. Jacobs for strain $\mathrm{mc}^{2} 155, \mathrm{Mr}$ Brad Low for help with the construction of the dnaA antisense vector, and Drs Mark Atkinson and Zafer Hatahet for helpful discussions and their interest during the course of this study. This work was supported in part by grants from the National Institutes of Health to M. V. V.S. M. (AI41406) and M.R. (AI48417). We thank the Institute of Genome Research for making the preliminary sequence data for M. smegmatis available to us.

\section{REFERENCES}

Ali Azam, T., Iwata, A., Nishhimura, A., Ueda, S. \& Ishihama, A. (1999). Growth phase-dependent variation in protein composition of the Escherichia coli nucleoid. J Bacteriol 181, 6361-6370.

Atlung, T., Clausen, E. \& Hansen, F. G. (1984). Autorepression of the dnaA gene of Escherichia coli. Adv Exp Med Biol 179, 199-207.

Atlung, T., Clausen, E. S. \& Hansen, F. G. (1985). Autoregulation of the dnaA gene of Escherichia coli K12. Mol Gen Genet 200, 442-450.

Bramhill, D. \& Kornberg, A. (1988a). Duplex opening by DnaA protein at novel sequences in initiation of replication at the origin of the E. coli chromosome. Cell 52, 743-755.

Bramhill, D. \& Kornberg, A. (1988b). A model for initiation at origins of DNA replication. Cell 54, 915-918.

Braun, R. E. \& Wright, A. (1986). DNA methylation differentially enhances the expression of one of the two Escherichia coli dnaA promoters in vivo and in vitro. Mol Gen Genet 202, 246-250.

Braun, R. E., O'Day, K. \& Wright, A. (1985). Autoregulation of the DNA replication gene dnaA in E. coli K-12. Cell 40, 159-169.

Cole, S. T., Brosch, R., Parkhill, J. \& 40 other authors (1998). Deciphering the biology of Mycobacterium tuberculosis from the complete genome sequence. Nature 393, 537-544.

Cook, W. R. \& Rothfield, L. I. (1999). Nucleoid-independent identification of cell division sites in Escherichia coli. J Bacteriol 181, 1900-1905.

Dick, T., Lee, B. H. \& Murugasu-Oei, B. (1998). Oxygen depletion induced dormancy in Mycobacterium smegmatis. FEMS Microbiol Lett 163, 159-164.

Donachie, W. D. (1993). The cell cycle of Escherichia coli. Annu Rev Microbiol 47, 199-230.

Dziadek, J., Madiraju, M. V., Rutherford, S. A., Atkinson, M. A. \& Rajagopalan, M. (2002a). Physiological consequences associated with overproduction of Mycobacterium tuberculosis FtsZ in mycobacterial hosts. Microbiology 148, 961-971.

Dziadek, J., Rajagopalan, M., Parish, T., Kurepina, N., Greendyke, R., Kreiswirth, B. N. \& Madiraju, M. V. (2002b). Mutations in the CCGTTCACA DnaA box of Mycobacterium tuberculosis oriC 
that abolish replication of oriC plasmids are tolerated on the chromosome. J Bacteriol 184, 3848-3855.

Gille, H. \& Messer, W. (1991). Localized DNA melting and structural perturbations in the origin of replication, oriC, of Escherichia coli in vitro and in vivo. EMBO J 10, 1579-1584.

Gomez, J. E. \& Bishai, W. R. (2000). whmD is an essential mycobacterial gene required for proper septation and cell division. Proc Natl Acad Sci U S A 97, 8554-8559.

Gorbatyuk, B. \& Marczynski, G. T. (2001). Physiological consequences of blocked Caulobacter crescentus dnaA expression, an essential DNA replication gene. Mol Microbiol 40, 485-497.

Hansen, F. G., Atlung, T., Braun, R. E., Wright, A., Hughes, P. \& Kohiyama, M. (1991). Initiator (DnaA) protein concentration as a function of growth rate in Escherichia coli and Salmonella typhimurium. J Bacteriol 173, 5194-5199.

Hinds, J., Mahenthiralingam, E., Kempsell, K. E., Duncan, K., Stokes, R. W., Parish, T. \& Stoker, N. G. (1999). Enhanced gene replacement in mycobacteria. Microbiology 145, 519-527.

Holz, A., Schaefer, C., Gille, H., Jueterbock, W. R. \& Messer, W. (1992). Mutations in the DnaA binding sites of the replication origin of Escherichia coli. Mol Gen Genet 233, 81-88.

Klann, A. G., Belanger, A. E., Abanes-De Mello, A., Lee, J. L. \& Hatful, G. F. (1998). Characterization of the $d n a G$ locus in Mycobacterium smegmatis reveals linkage of DNA replication and cell division. J Bacteriol 180, 65-72.

Kornberg, A. \& Baker, T. (1991). DNA Replication. New York: W. H. Freeman.

Langer, U., Richter, S., Roth, A., Weigel, C. \& Messer, W. (1996). A comprehensive set of DnaA-box mutations in the replication origin, oriC, of Escherichia coli. Mol Microbiol 21, 301-311.

Lee, L.-F., Yeh, S.-H. \& Chen, C. W. (2002). Construction and synchronization of $d n a A$ temperature-sensitive mutants of Streptomyces. J Bacteriol 184, 1214-1218.

Madiraju, M. V., Qin, M. H., Yamamoto, K., Atkinson, M. A. \& Rajagopalan, M. (1999). The dnaA gene region of Mycobacterium avium and the autonomous replication activities of its $5^{\prime}$ and $3^{\prime}$ flanking regions. Microbiology 145, 2913-2921.

Manabe, Y. C. \& Bishai, W. R. (2000). Latent Mycobacterium tuberculosis - persistence, patience, and winning by waiting. Nat Med 6, 1327-1329.

Marszalek, J. \& Kaguni, J. M. (1994). DnaA protein directs the binding of DnaB protein in initiation of DNA replication in Escherichia coli. J Biol Chem 269, 4883-4890.

Messer, W. \& Weigel, C. (1997). DnaA initiator - also a transcription factor. Mol Microbiol 24, 1-6.

Messer, W., Seufert, W., Schaefer, C., Gielow, A., Hartmann, H. \& Wende, M. (1988). Functions of the DnaA protein of Escherichia coli in replication and transcription. Biochim Biophys Acta 951, 351-358.

Messer, W., Blaesing, F., Jakimowicz, D. \& 10 other authors (2001). Bacterial replication initiator DnaA. Rules for DnaA binding and roles of DnaA in origin unwinding and helicase loading. Biochimie 83, 5-12.

Moriya, S., Kato, K., Yoshikawa, H. \& Ogasawara, N. (1990). Isolation of a dnaA mutant of Bacillus subtilis defective in initiation of replication: amount of DnaA protein determines cells' initiation potential. EMBO J 9, 2905-2910.

Noirot-Gros, M. F., Dervyn, E., Wu, L. J., Mervelet, P., Errington, J., Ehrlich, S. D. \& Noirot, P. (2002). An expanded view of bacterial DNA replication. Proc Natl Acad Sci U S A 99, 8342-8347.

Ogura, Y., Imai, Y., Ogasawara, N. \& Moriya, S. (2001).
Autoregulation of the $d n a A-d n a N$ operon and effects of DnaA protein levels on replication initiation in Bacillus subtilis. J Bacteriol 183, 3833-3841.

Parish, T. \& Stoker, N. G. (2000). Use of a flexible cassette method to generate a double unmarked Mycobacterium tuberculosis tly A plcABC mutant by gene replacement. Microbiology 146, 19691975.

Parish, T., Mahenthiralingam, E., Draper, P., Davis, E. O. \& Colston, M. J. (1997). Regulation of the inducible acetamidase gene of Mycobacterium smegmatis. Microbiology 143, 22672276.

Polaczek, P. \& Wright, A. (1990). Regulation of expression of the dnaA gene in Escherichia coli: role of the two promoters and the DnaA box. New Biol 2, 574-582.

Qin, M. H., Madiraju, M. V., Zachariah, S. \& Rajagopalan, M. (1997). Characterization of the oriC region of Mycobacterium smegmatis. J Bacteriol 179, 6311-6317.

Qin, M. H., Madiraju, M. V. \& Rajagopalan, M. (1999). Characterization of the functional replication origin of Mycobacterium tuberculosis. Gene 233, 121-130.

Rajagopalan, M., Qin, M. H., Nash, D. R. \& Madiraju, M. V. (1995). Mycobacterium smegmatis dnaA region and autonomous replication activity. J Bacteriol 177, 6527-6535.

Ratledge, C. (1976). The physiology of the mycobacteria. Adv Microb Physiol 13, 115-244.

Richter, S., Hess, W. R., Krause, M. \& Messer, W. (1998). Unique organization of the $d n a A$ region from Prochlorococcus marinus CCMP1375, a marine cyanobacterium. Mol Gen Genet 257, 534-541.

Salazar, L., Fsihi, H., de Rossi, E., Riccardi, G., Rios, C., Cole, S. T. \& Takiff, H. E. (1996). Organization of the origins of replication of the chromosomes of Mycobacterium smegmatis, Mycobacterium leprae and Mycobacterium tuberculosis and isolation of a functional origin from M. smegmatis. Mol Microbiol 20, 283-293.

Sambrook, J., Fritsch, E. F. \& Maniatis, T. (1989). Molecular Cloning: a Laboratory Manual, 2nd edn. Cold Spring Harbor, NY : Cold Spring Harbor Laboratory.

Schaper, S. \& Messer, W. (1997). Prediction of the structure of the replication initiator protein DnaA. Proteins 28, 1-9.

Skarstad, K. \& Boye, E. (1994). The initiator protein DnaA: evolution, properties and function. Biochem Biophys Acta 1217, 111-130.

Skovgaard, O., Olesen, K. \& Wright, A. (1998). The central lysine in the P-loop motif of the Escherichia coli DnaA protein is essential for initiating DNA replication from the chromosomal origin, ori $\mathrm{C}$, and the $\mathrm{F}$ factor origin, oriS, but is dispensable for initiation from the P1 plasmid origin, oriR. Plasmid 40, 91-99.

Smith, R. W., McAteer, S. \& Masters, M. (1997). Autoregulation of the Escherichia coli replication initiator protein, DnaA, is indirect. Mol Microbiol 23, 1303-1315.

Snapper, S. B., Lugosi, L., Jekkel, A., Melton, R. E., Kieser, T., Bloom, B. R. \& Jacobs, W. R., Jr (1988). Lysogeny and transformation in mycobacteria: stable expression of foreign genes. Proc Natl Acad Sci US A 85, 6987-6991.

Stover, C. K., de la Cruz, V. F., Fuerst, T. R. \& 11 other authors (1991). New use of BCG for recombinant vaccines. Nature 351, 456-460.

Stover, C. K., Bansal, G. P., Hanson, M. S. \& 7 other authors (1993). Protective immunity elicited by recombinant bacille Calmette-Guerin (BCG) expressing outer surface protein A (OspA) lipoprotein : a candidate Lyme disease vaccine. J Exp Med 178, 197-209. 
Sun, Q. \& Margolin, W. (2001). Influence of the nucleoid on placement of FtsZ and MinE rings in Escherichia coli. J Bacteriol 183, 1413-1422.

Triccas, J. A., Parish, T., Britton, W. J. \& Gicquel, B. (1998). An inducible expression system permitting the efficient purification of a recombinant antigen from Mycobacterium smegmatis. FEMS Microbiol Lett 167, 151-156.

Wayne, L. G. (1977). Synchronized replication of Mycobacterium tuberculosis. Infect Immun 17, 528-530.

Wayne, L. G. (1994). Dormancy of Mycobacterium tuberculosis and latency of disease. Eur J Clin Microbiol Infect Dis 13, 908-914.
Wayne, L. G. \& Hayes, L. G. (1996). An in vitro model for sequential study of shiftdown of Mycobacterium tuberculosis through two stages of nonreplicating persistence. Infect Immun 64, 2062-2069.

Yamamoto, K., Muniruzzaman, S., Rajagopalan, M. \& Madiraju, M. V. (2002). Modulation of Mycobacterium tuberculosis DnaA protein-adenine-nucleotide interactions by acidic phospholipids. Biochem J 363, 305-311.

Zyskind, J. W. \& Smith, D. W. (1992). DNA replication, the bacterial cell cycle, and cell growth. Cell 69, 5-8.

Received 27 June 2002; revised 30 July 2002; accepted 27 August 2002. 